\title{
Stereo CUTLASS - A new capability for the SuperDARN HF radars
}

\author{
M. Lester ${ }^{1}$, P. J. Chapman ${ }^{2}$, S. W. H. Cowley ${ }^{1}$, S. J. Crooks ${ }^{1}$, J. A. Davies ${ }^{1,3}$, P. Hamadyk ${ }^{1}$, K. A. McWilliams ${ }^{4}$, \\ S. E. Milan ${ }^{1}$, M. J. Parsons ${ }^{1}$, D. B. Payne ${ }^{1}$, E. C. Thomas ${ }^{1}$, J. D. Thornhill ${ }^{1}$, N. M. Wade $^{1}$, T. K. Yeoman ${ }^{1}$, and \\ R. J. Barnes ${ }^{5}$ \\ ${ }^{1}$ Department of Physics and Astronomy, University of Leicester, Leicester, LE1 7RH, UK \\ ${ }^{2}$ Department of Communications Systems, Lancaster University, Bailrigg, Lancaster, LA1 4YR, UK \\ ${ }^{3}$ now at: Space Science Department, Rutherford Appleton Laboratory, Chilton, Didcot, Oxon, OX11 0QX, UK \\ ${ }^{4}$ Department of Physics and Engineering Physics, University of Saskatchewan, 116 Science Place, Saskatoon, Saskatchewan, \\ S7N 5E2, Canada \\ ${ }^{5}$ Applied Physics Laboratory, Johns Hopkins University, 11100 Johns Hopkins Road, Laurel, Maryland, 20723-6099, USA
}

Received: 16 April 2003 - Revised: 19 June 2003 - Accepted: 23 June 2003 - Published: 1 January 2004

\begin{abstract}
The Super Dual Auroral Radar Network (SuperDARN), which consists of networks of HF radars surrounding the northern and southern poles, has proven to be an extremely successful experimental technique in a wide range of scientific areas. The basic design of the radars, which contributes to SuperDARN, has remained virtually unchanged since the first radar was built in the early 1980s. This paper presents the first results of a significant new development of the basic system. Termed "Stereo", this development involves the addition of a duplicate receive channel and makes use of the spare duty cycle available in the current transmitters. The Stereo system has been implemented on the two radars that form the Co-operative UK Twin Located Auroral Sounding System (CUTLASS), which are the easternmost pair of radars in the Northern Hemisphere SuperDARN chain. Instead of the standard 7 pulse sequence normally employed by the radars, two such pulse sequences are interleaved and transmitted at different frequencies separated by more than $15 \mathrm{kHz}$. This development allows for the radar to run two entirely different experimental modes simultaneously. Here we describe the basic Stereo system and some of the early results. We also identify potential new experiments which could be run with Stereo to complement the existing standard SuperDARN radar.
\end{abstract}

Key words. Ionosphere (ionosphere-magnetosphere interactions; ionospheric irregularities; instruments and techniques)

\section{Introduction}

The HF radars that form the Super Dual Auroral Radar Network, SuperDARN, (Greenwald et al., 1995) have made major contributions in a number of scientific areas. These in-

Correspondence to: M. Lester(mle@ion.le.ac.uk) clude, amongst others, the study of ionospheric convection driven by transient reconnection, or flux transfer events (e.g. Pinnock et al., 1993; Provan et al., 1998; Neudegg et al., 1999, 2000; Wild et al., 2001; Davies et al., 2002), the estimation of the reconnection rates at the dayside magnetopause from the resulting flows and changes in the location of the polar cap boundary (e.g. Baker et al., 1997; Chisham et al., 2002), the study of flows associated with optical transients in the dayside cusp (e.g. Milan et al., 2000; Thorolfsson et al., 2000), the investigation of flows in the nightside ionosphere during substorms (e.g. Yeoman et al., 2000; Bristow et al., 2001), the discovery of unusually high velocities in the nightside ionosphere (Walker et al., 1998; Senior et al., 2002; Grocott et al., 2003), the derivation of the average flow pattern associated with different orientations of the interplanetary magnetic field (IMF) (Ruohoniemi and Greenwald, 1996), the study of E-region irregularities (e.g. Milan and Lester, 2001; Milan et al., 2001; Makarevitch et al., 2002), the investigation of atmospheric gravity waves (e.g. Bristow et al., 1994; Arnold et al., 1998), the derivation of neutral winds from the scatter from ionisation trails of meteors (Hall et al., 1997; Arnold et al., 2001) and the study of artificially generated irregularities using the high power radio wave transmitter, or heater, at Troms $\varnothing$ (Robinson et al., 1997; Yeoman et al., 1997). Considerable effort has been placed recently in the use of sophisticated analysis techniques to provide the global convection pattern at a time resolution of typically 2 min (Ruohoniemi and Baker, 1998), as well as developing a near-real time capability for Space Weather purposes (e.g. Ruohoniemi et al., 2001) and investigating real time channel characteristics for HF propagation (Hughes et al., 2002). In addition, use has been made of other parameters derived from the radar autocorrelation function, such as the spectral width, to identify the ionospheric footprint of magnetospheric boundaries (e.g. Baker et al., 1995; Dudeney et al., 1998; Lester et al., 2001; Woodfield et al., 2002). 


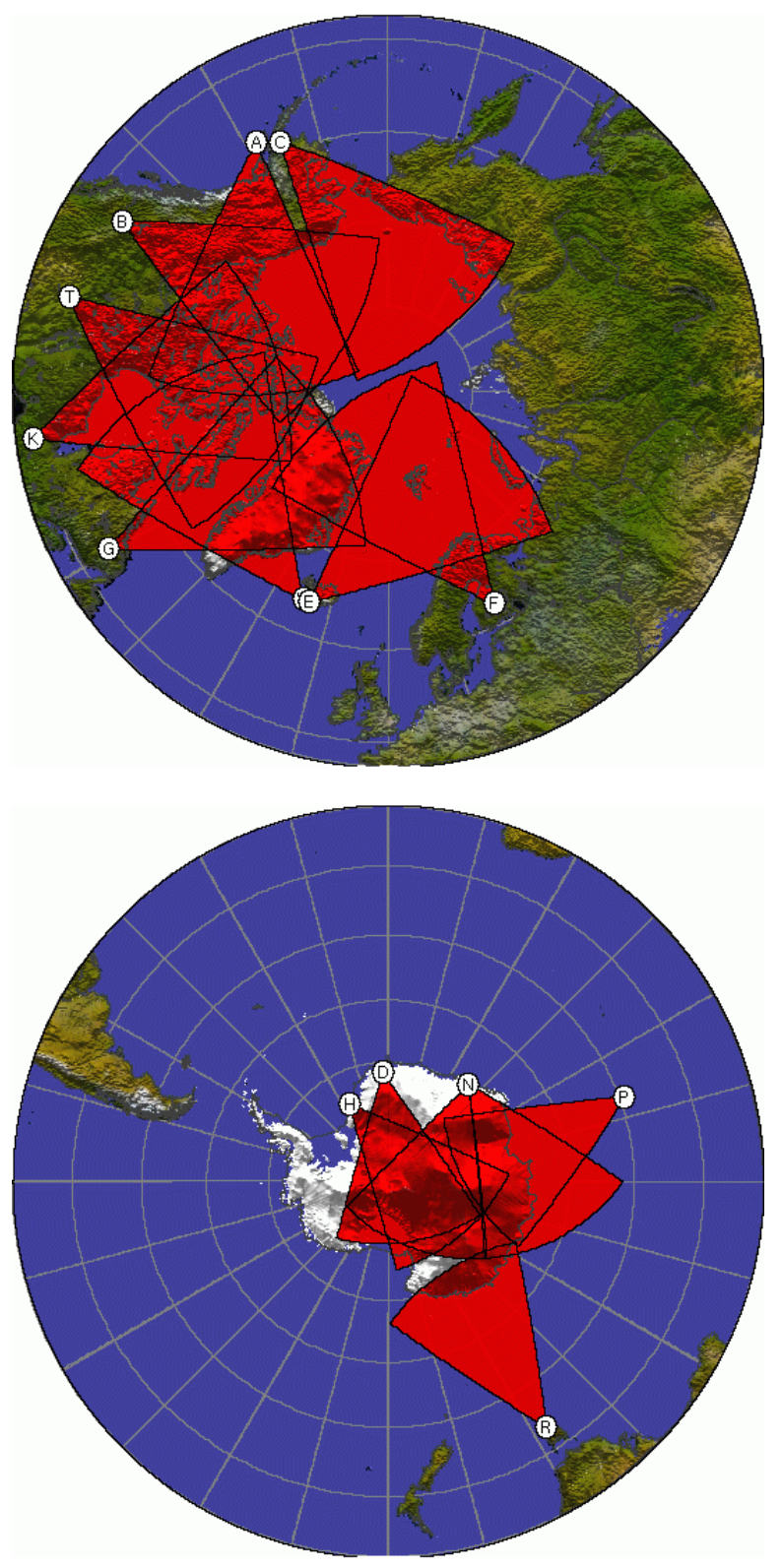

Fig. 1. Maps showing the fields of view of the SuperDARN radars in the Northern Hemisphere (top panel) and Southern Hemisphere (bottom panel). The CUTLASS radars, identified as E and F, form the easternmost pair in the Northern Hemisphere.

Although there have been many scientific advances made with SuperDARN, the basic radar system has remained essentially unchanged since the first radar was built in the early 1980s (Greenwald et al., 1985). There have been minor technical upgrades to the basic radar design with the development of each new radar joining the network, largely to improve operational reliability, but there have been no significant technical changes to the actual radar operations of the original system. Recently, however, there has been a development which significantly changes the way in which these radars can operate. This development, termed "Stereo" as it effectively dou- bles the sounding capability of the system, has been installed on the two radars which form the Co-operative UK Twin Located Auroral Sounding System (CUTLASS) at Hankasalmi in Finland and Pykkvibaer in Iceland. A description of this development, together with some of the first results and plans for the future use of the Stereo system, form the basis of this paper.

\section{The Stereo CUTLASS system}

\subsection{The original SuperDARN radar system}

Before discussing in detail the Stereo concept and system, it is worthwhile reviewing the technical aspects of the basic SuperDARN radar system (for a more complete description, see Greenwald et al., 1995). Each SuperDARN radar comprises a phased array radar operating in the frequency range 8 to $20 \mathrm{MHz}$, although due to transmit licence considerations, the radars are constrained to operate in selected frequency bands, and in the case of the CUTLASS radars these are typically $100 \mathrm{kHz}$ wide in approximate steps of $1 \mathrm{MHz}$. Each radar employs 16 horizontally polarised log periodic antennas, each driven by a $600 \mathrm{~W}$ pulse transmitter which includes a Receive/Transmit (Rx/Tx) switch to allow for the antenna array to be used to both receive and transmit. A bidirectional beam forming network, consisting of switched, fixed time delays, allows any one of 16 possible pointing directions to be selected for both transmission and reception of signals. A dual channel receiver and a reference signal source are connected via a further Rx/Tx switch. A second, receive only, interferometer array, consisting of 4 antennas similar to those in the main array, is deployed at some sites, to allow for the measurement of the elevation angle of the arrival of backscattered radar signals. SuperDARN radars typically employ a seven-pulse sequence with an individual pulse length of 300 microseconds, corresponding to a range resolution of $45 \mathrm{~km}$, from which the autocorrelation function (ACF) is determined in normal mode for ranges from 180 to at least $3230 \mathrm{~km}$, depending upon the number of gates. The Doppler shift is determined by a phase fitting procedure to provide the line of sight velocity of the irregularities from which the radar signal is scattered within a range which varies from about $\pm 3000 \mathrm{~m} \mathrm{~s}^{-1}$ to $\pm 1800 \mathrm{~m} \mathrm{~s}^{-1}$, depending upon operating frequency, with a resolution of the order of $10 \mathrm{~m} \mathrm{~s}^{-1}$. Backscatter power and spectral width are determined from a functional fit to the autocorrelation function. In normal operating mode, the radars dwell on each of the 16 beams for $7 \mathrm{~s}$, scanning consecutively across the 16 beam directions. Each full scan starts on a GPS synchronised two-minute boundary, to ensure that all radars in the network start the scan simultaneously. An alternative high-time resolution common mode employs a 3-s dwell on each beam direction and a one-minute synchronization.

Currently, there are 9 operational SuperDARN radars in the Northern Hemisphere and 6 in the Southern Hemisphere (Fig. 1). In the original SuperDARN concept, the radars were 


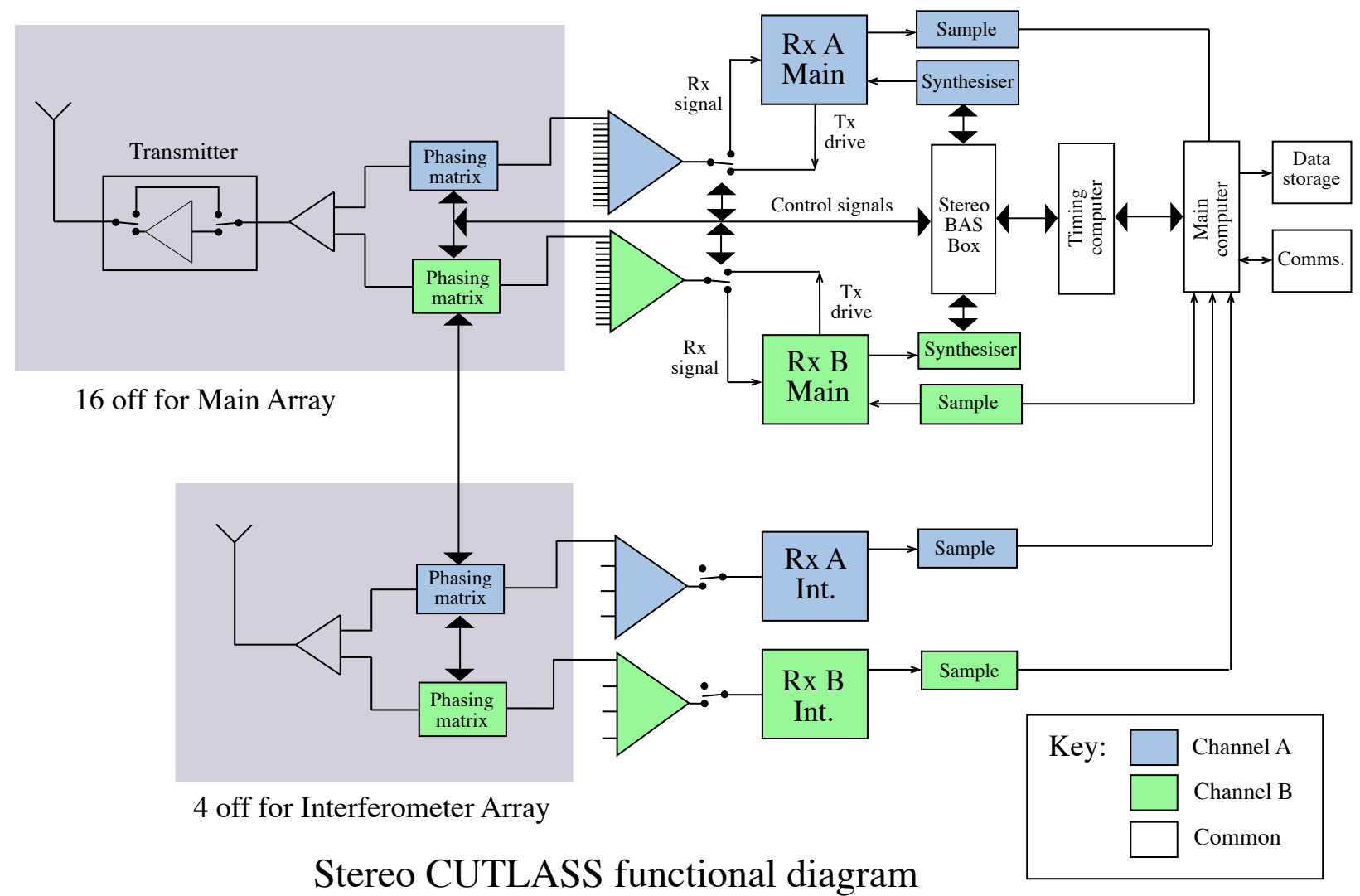

Fig. 2. Schematic representation of the Stereo system.

located such that they had overlapping fields of view which could provide two-dimensional measurements of the vector velocity. Although all follow the same fundamental design, and use the same operating software, there are slight differences between the various radars, as they have been built over a period of 20 years, starting with the Goose Bay radar (Greenwald et al., 1985). The most recent radars are referred to as Type 3, which is a specific design configuration of a $\mathrm{Su}$ perDARN radar developed at the University of Leicester for CUTLASS (radars E and F in Fig. 1, upper panel), which has been used as a basis for the implementation of several recent radars, e.g. TIGER (radar R in Fig. 1, lower panel) and King Salmon (radar C in Fig. 1, upper panel).

This basic system is in fact quite flexible. Different scanning patterns can be performed, different range resolutions are possible and the distance to the first range gate can be changed to investigate certain areas within the larger field of view. Moreover, the dwell time on a beam can be reduced to $1 \mathrm{~s}$. Despite this flexibility, the system is still limited to some extent. This limitation stems mainly from the success of the radars in being able to investigate such a diverse range of scientific topics. The main scientific objective of SuperDARN is to investigate the large-scale, ionospheric convection pattern, and therefore, the normal scan, with either 2-min or 1min scan times, has to be run for the bulk of the time on all radars. This requirement also leads to large $(45 \mathrm{~km})$ range gates, to ensure that the largest possible coverage can be achieved. Thus, any other scientific investigation, for example to study artificially stimulated irregularities, with higher temporal resolution and improved range resolution, or ULF waves, with higher time resolution, tends to have a lower priority. In order to allow for such studies to be undertaken, a proportion of time (currently up to 50\%) each month is devoted to non-standard experimental modes.

\subsection{The Stereo system}

Stereo CUTLASS was developed to provide both additional flexibility to the basic system, as well as to improve the temporal resolution of the basic CUTLASS SuperDARN radars. Stereo relies on the capability of the transmitters in Type 3 SuperDARN radars to operate at duty cycles of at least 7\%, twice that required for normal SuperDARN operations. Stereo essentially consists of two radar channels, each of which is able to transmit and receive independent signals but which share common transmitters, antennas and control system. Radar pulses from each channel are differentiated by their frequency, and it is necessary to use separate signal generation, beam forming and receivers in each of the two channels. The common components, however, constitute the major capital cost within a SuperDARN radar so Stereo is significantly cheaper than two radars.

The Stereo implementation is illustrated in Fig. 2, which is a functional representation of the complete system. The com- 
ponents of the system which are common to both channels are in white, while the elements which are required for each channel are shown in blue (channel A) and green (channel B). The original configuration is extended by the duplication of the phasing matrix, receiver and transmit signal generation. A new version of an interface box, termed a "BAS box", which was originally a hardwired patch panel providing convenient interconnection of control signals throughout the system, has been developed. The Stereo BAS box adds arbitration logic to protect the system from requests to transmit on both channels simultaneously and to ensure that the $\mathrm{Rx} / \mathrm{Tx}$ switch in each Stereo channel is set with regard to transmit requests in both channels. By default, both channels are able to receive simultaneously but neither channel is able to receive whilst either of the channels is transmitting. The new Stereo BAS box also incorporates remote monitoring of potential conflicts detected by the arbitration logic, as well as the aggregated duty cycle, operating frequency and beam direction.

A second analogue to digital (A/D) interface is provided within the main computer, to allow for the additional four channels of analogue In-phase and Quadrature (I/Q) signals, for both the main and interferometer receivers to be simultaneously sampled. The original timing computer, which acts as a programmable timing signal generator, includes the ability to generate the required signals for both Stereo channels. The most recent version of the radar operating system, RST, developed at the Applied Physics Laboratory (APL), Johns Hopkins University, includes the ability to operate Stereo CUTLASS, as well as normal SuperDARN radars.

In operation, Stereo sets the beam direction for each of the two channels, which may be the same or different, by sending the appropriate control signals to the two phasing matrices. The timing computer generates individual, nonoverlapping pulse sequences for each of the two channels. The conceptually simplest arrangement is to use the same pulse pattern on both channels, with one delayed with respect to the other by a time greater than a single pulse period, which is 300 microseconds in normal mode. These pulse sequences generate equivalent RF drive signals at different transmit frequencies, and these are routed through the phasing matrices and $\mathrm{Rx} / \mathrm{Tx}$ switches to the transmitters which generate the appropriately phased signals in the antenna array. When not transmitting, the received signals are routed back through the phasing matrices to the receivers and the down converted signals are sampled by the main computer. The autocorrelation function for each pulse sequence is averaged over the dwell period, and the normal procedures are used to determine power, velocity and spectral width parameters for both of the Stereo channels. The process continues for as many pointing directions as required in an individual scan and the interleaved data from both Stereo channels are recorded to disk.

Stereo CUTLASS provides effectively two equivalent independent radars, though this system does have some limitations caused by hardware constraints. The two channels must operate at different frequencies to ensure that backscat- tered signals from one channel are not confused with those from the other channel. The CUTLASS radars have limited frequency bands in which they can operate which are often not wider than $100 \mathrm{kHz}$. If Stereo CUTLASS operates both channels in the same frequency band, the separation in frequency must be greater than the receiver bandwidth of $15 \mathrm{kHz}$. It is also possible for Stereo to operate in two entirely different frequency bands.

\subsection{Impact of Stereo on the AutoCorrelation Function (ACF)}

One of the major concerns for the new system is the potential impact on the ACF, which is formulated by constructing a set of "lags" from the pulse sequence. Some of these lags, referred to as "bad lags", can be missing or non-physical, and these are caused by a variety of mechanisms. Two of these mechanisms are independent of the second pulse train while the third is very much dependent upon both pulse trains, and hence, the impact of additional pulse trains, such as that found in the Stereo system, has to be considered.

Multi-pulse radars, such as those which form part of SuperDARN, coherently integrate over a number of pulse sequences to derive the ACF. Since signals from different ranges are random with respect to signals from the same range but arising from different pulses, averaging leaves only information about temporal changes within a single range gate and gives rise to a minimum temporal resolution of order $1 \mathrm{~s}$ for SuperDARN radars, corresponding to approximately 10 pulse sequences. Additional processing, however, is required to overcome problems when signals from other ranges for specific lag times are significantly greater than those from the wanted range cell and where significant contamination of the ACF must be identified and removed. Cross range noise is illustrated in the lower panel of Fig. 3, where the standard pulse sequence is represented by the small vertical lines just beneath the main panel. The diagonal lines represent the propagation of selected pulses (1-5) outward from the radar and back again after scattering from selected ranges. The smallest interpulse period for this pulse sequence is 2400 microseconds and for the complete pulse sequence to be received from all 70 range gates takes 88 milliseconds. We see that the second pulse from range gate 45 is received uniquely, whereas that from range gate 31 arrives at the same time as the third pulse from range gate 7 . Other similar examples are also shown with pulses 4 and 5 , which demonstrate that this can happen at a variety of different range gates and pulses in the train. The major problem occurs when there is power being received from both range gates, as the receiver cannot then distinguish between the two. The extra pulses from Stereo do not impact here, provided that the separation of the two pulse trains is not an integer multiplier of the basic lag separation. The other problem that is not exacerbated by the Stereo operation is the occurrence of non-physical ACFs. Since we expect the ACF to decay in amplitude, then additional power than expected at later lags would cause such an ACF. Such additional power might be caused by interference 

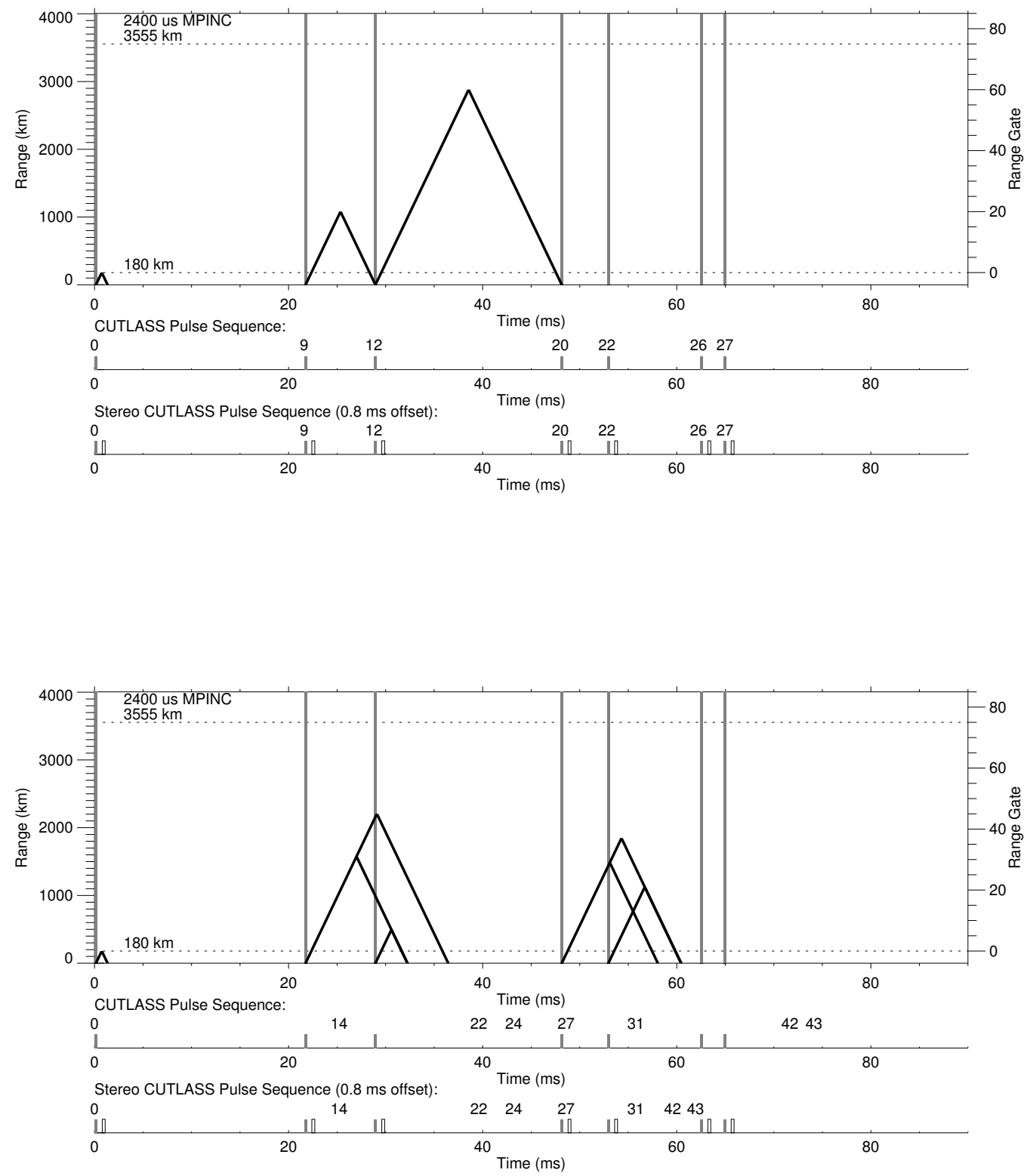

Fig. 3. Range time plot for the standard pulse sequence at a basic pulse separation of 2400 microseconds, together with the standard pulse sequence and the Stereo pulse sequence. The top panel illustrates the problem associated with bad lags generated by the overlap of the receipt of a pulse and the transmission of a pulse. The lower panel illustrates the problem of cross range noise.

from another HF source. Both these bad lag mechanisms are accounted for in the standard SuperDARN ACF fitting software (termed fitacf).

The mechanism which might seriously impact Stereo operations results from the inability to receive and transmit simultaneously. This is illustrated in the top panel of Fig. 3, which is in the same format as the lower panel. If we consider the first pulse of the sequence, we see that it is received from the first range gate (identified as gate 0) a short time after the pulse has been transmitted. This is not a problem, as there are no other pulses being transmitted at that time. If, however, we consider the second pulse propagated out to gate 20 and scattered back to the radar, we see that it is re- ceived at a time when the third pulse is being transmitted. Since the Stereo system is unable to transmit and receive at the same time, the second pulse from this range will not be received. Likewise, the third pulse for gate 60 is received at the time that the fourth pulse in the sequence is being transmitted. Thus, for certain gates there will be certain pulses which are not received and, therefore, certain lags will not be able to be formed in the autocorrelation function. By increasing the number of pulses being sent, the number of occasions when a pulse cannot be received is increased. The missing lags caused by this problem are easily predicted and do not normally prevent data fitting, provided that the fitting process takes them intoaccount. A simple software modification 


\section{SUPERDARN PARAMETER PLOT}

Hankasalmi: Channel 1 and Channel 2 (alternating)
17 Nov $2000^{(322)}$

normal (ccw) scan mode (150)

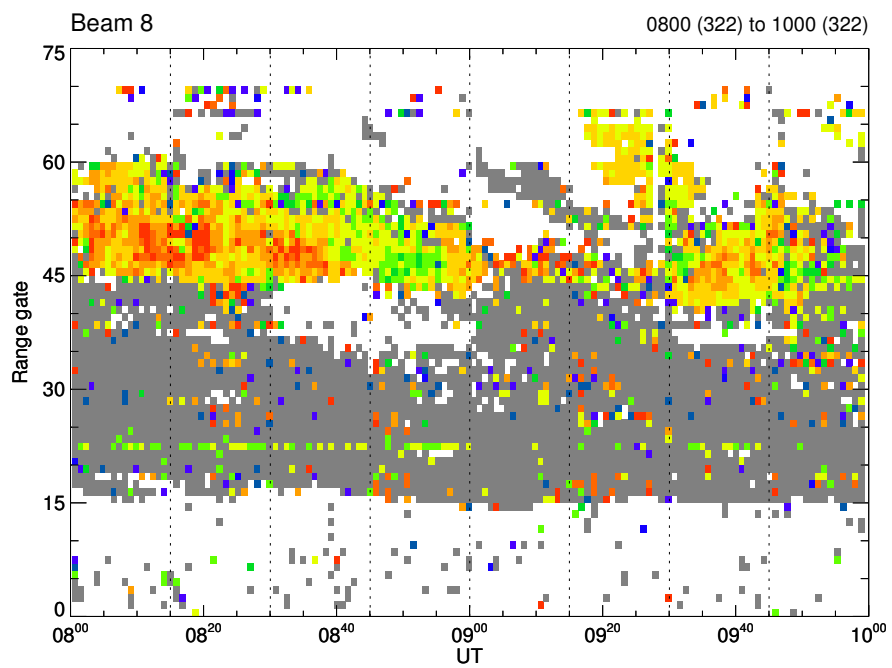

800

600

400

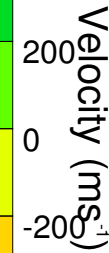

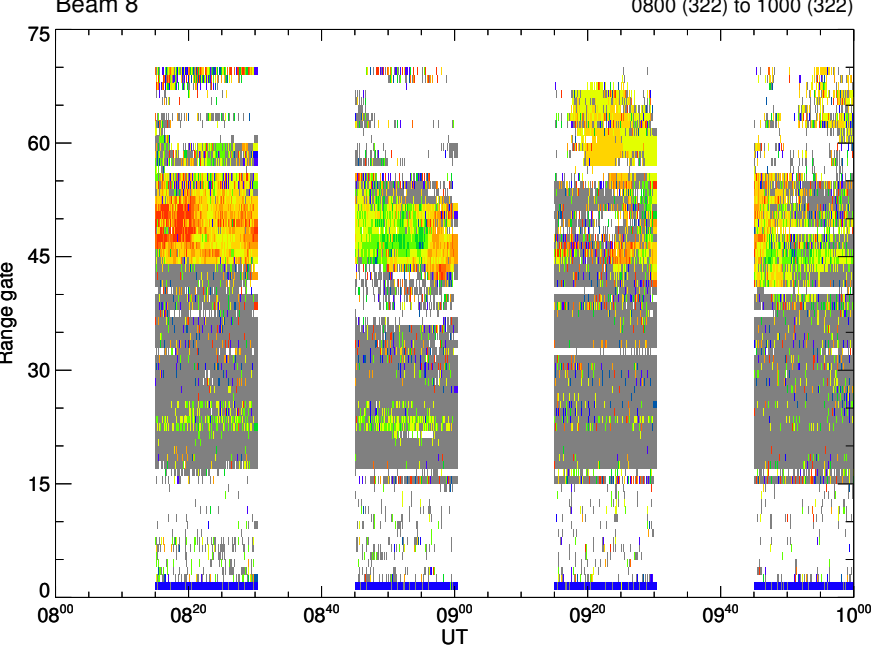

$-400$

$-600$

$-800$

Ground

Scatter

Fig. 4. Range time velocity plots of the line of sight velocity measured between 08:00 and 10:00 UT on 17 November 2000 on beam 8 of the Hankasalmi radar. The top panel presents data from channel A and the lower panel from channel B. The radar was alternating between mono and stereo operation, the start times of which are illustrated by dashed vertical lines in the top panel. Ground scatter is coded as grey.

to existing SuperDARN analysis software has been made for Stereo system operations. The Stereo pulse sequence, with a separation of 800 microseconds between pulse trains, is shown below the standard pulse sequence in Fig. 3. Note that $800 \mu \mathrm{s}$ is chosen for clarity in the figure, while $400 \mu \mathrm{s}$ is typically used in Stereo operations.

The impact of not being able to receive and transmit simultaneously is further illustrated in Fig. 4, where we present Doppler velocity data from an early test run of Stereo in which the Finland radar was switched between mono and Stereo operation every $15 \mathrm{~min}$. The upper panel of Fig. 4 presents data from Channel 1 of Stereo, which also includes the data from the mono operation, while the data from Chan- nel 2 of Stereo is presented in the lower panel. The switch from mono to Stereo operation is clearly defined by the existence of data in the lower panel. The data have been analysed using the original version of the software, to identify the "bad lags". The experimental mode run during this test run was a simple normal scan on channel A, while on channel B, during the stereo part of the experiment, the radar simply "camped" on one beam, beam 8 , and hence, the data in the lower panel is at a higher time resolution than that in the upper panel.

First, it is important to note that there is no clear difference in channel A between the data from the mono and Stereo operations. Thus, we see that there is no significant impact on the channel A data. Investigating the lower panel of Fig. 4 we 
see that there are two main effects. The first is the band of apparent scatter at the first range, which is clearly an instrumental effect and can be removed by suitable choice of the offset between the two channels. The second effect concerns range gates where there has been no fit to the data due to an increase in the number of bad lags identified by the analysis software. These are identified as horizontal lines where no signal appears to have been measured at a fixed range gate despite the range gate being in the middle of either ionospheric or ground scatter. In later figures we present data which have been analysed with the modified software mentioned above and although such regions do exist, the number has been reduced. Thus, although the impact is small, affecting approximately 6 range gates out of 70 , it is still observable and demonstrates the need for the modified analysis software for Stereo operations.

\section{Observational results}

SuperDARN radars have demonstrated the unique ability to generate maps of irregularities with high-time resolution over extended regions during normal operation. This ability is significantly enhanced by the second Stereo channel, which may be programmed to provide additional information without impacting normal scanning. Some of the possible applications are as follows:

- The ability to operate at two frequencies to maximise coverage, otherwise limited due to HF propagation conditions.

- The provision of a second beam with either a fixed look direction with temporal resolution of up to one second or a limited beam scan to provide simultaneous spatial and temporal views.

- Interleaved beam scanning using both channels to decrease the full scan time down to $8 \mathrm{~s}$ (with 1-s dwell time on each beam).

- The provision of a second channel with different range resolution or range extent.

- The ability to program the second channel to extract neutral wind velocity from meteor scatter whilst making standard measurements on the first channel.

We now illustrate the capabilities of the Stereo system with some examples of the data collected to date when Stereo has been operated in a variety of modes. It should be mentioned that it is not the purpose to provide a detailed scientific analysis of the data here, but simply to illustrate the capability of the Stereo system. Where applicable, reference is made to papers where a more detailed scientific analysis is presented.

\subsection{High time resolution single beam and full scan}

The mode which has been run most often during the initial operations of Stereo is a standard full scan on channel A, i.e. 7-s dwell time and 2-min scan time, with a single beam on channel B. The single beam on channel B has a time resolution of $7 \mathrm{~s}$, comparable with magnetometer measurements. Range Time Parameter plots of backscatter power, line of sight velocity, and spectral width from such a run are presented in Fig. 5 from Hankasalmi (Fig. 5a) and Pykkvibaer (Fig. 5b). In this run, the single beam on channel B chosen for Hankasalmi was beam 9 (Fig. 5a, right-hand column) while for Pykkvibaer it was beam 5 (Fig. 5b, right-hand column). The left-hand columns present data from the same two beams but from the standard mode. We see from the data presented in Fig. 5 that the agreement between the two beams is good, as expected. However, we also note that there is considerably more detail in the high-time resolution data which cannot be obtained from the standard scan.

This extra detail is demonstrated more clearly in Fig 6, where line plots for a single range cell are presented in the same format as in Fig 5. In Fig. 6a, the Hankasalmi data from gate 31 of beam 9 from the channel A full scan (lefthand column) demonstrate that the line of sight velocity was of the order of $500 \mathrm{~m} \mathrm{~s}^{-1}$ for much of the selected one-hour interval (03:00-04:00 UT). The channel B high-time resolution beam (right-hand column) clearly indicates that while this is true, there is much more structure than could previously be recognized. The same is true of the spectral width parameter, shown in the bottom panel of each column. This observation is further supported by the data from Fig. 6b, where Pykkvibaer data are presented for the interval 01:30 to 03:00 UT. A difference between the spectral width data early on in the interval, between 01:45 and 01:55 UT, is quite clear, indicating that structure can be missed with the full scan. In the full scan data the values are initially of the order of $200 \mathrm{~m} \mathrm{~s}^{-1}$, but the high-time resolution mode indicates that the spectral width is often greater than $300 \mathrm{~m} \mathrm{~s}^{-1}$ and can reach $600 \mathrm{~m} \mathrm{~s}^{-1}$. Such a result may be of importance when using the spectral width parameter to identify regions such as the cusp (e.g. Baker et al., 1995) or polar cap boundary (e.g. Lester et al., 2001; Woodfield et al., 2002).

\subsection{Comparison of $45-\mathrm{km}$ and $15-\mathrm{km}$ range gates}

As mentioned earlier, in normal operation the SuperDARN radars operate a 7-pulse sequence with an individual pulse length of 300 microseconds, which is equivalent to a range resolution of $45 \mathrm{~km}$. The range to the first gate is normally $180 \mathrm{~km}$, and 70 gates are normally recorded. The individual pulse length can be reduced to 200 or 100 microseconds, equivalent to range gates of length 30 or $15 \mathrm{~km}$, respectively, but 70 gates are still recorded. The reduction in gate length, therefore, has the disadvantage currently of reducing the overall spatial coverage. A number of modes require the ability to run with higher spatial resolution. Examples include the radar modes run in support of heating experiments 
SUPERDARN PARAMETER PLOT

2 Jun $2002^{(153)}$

Hankasalmi: width_I
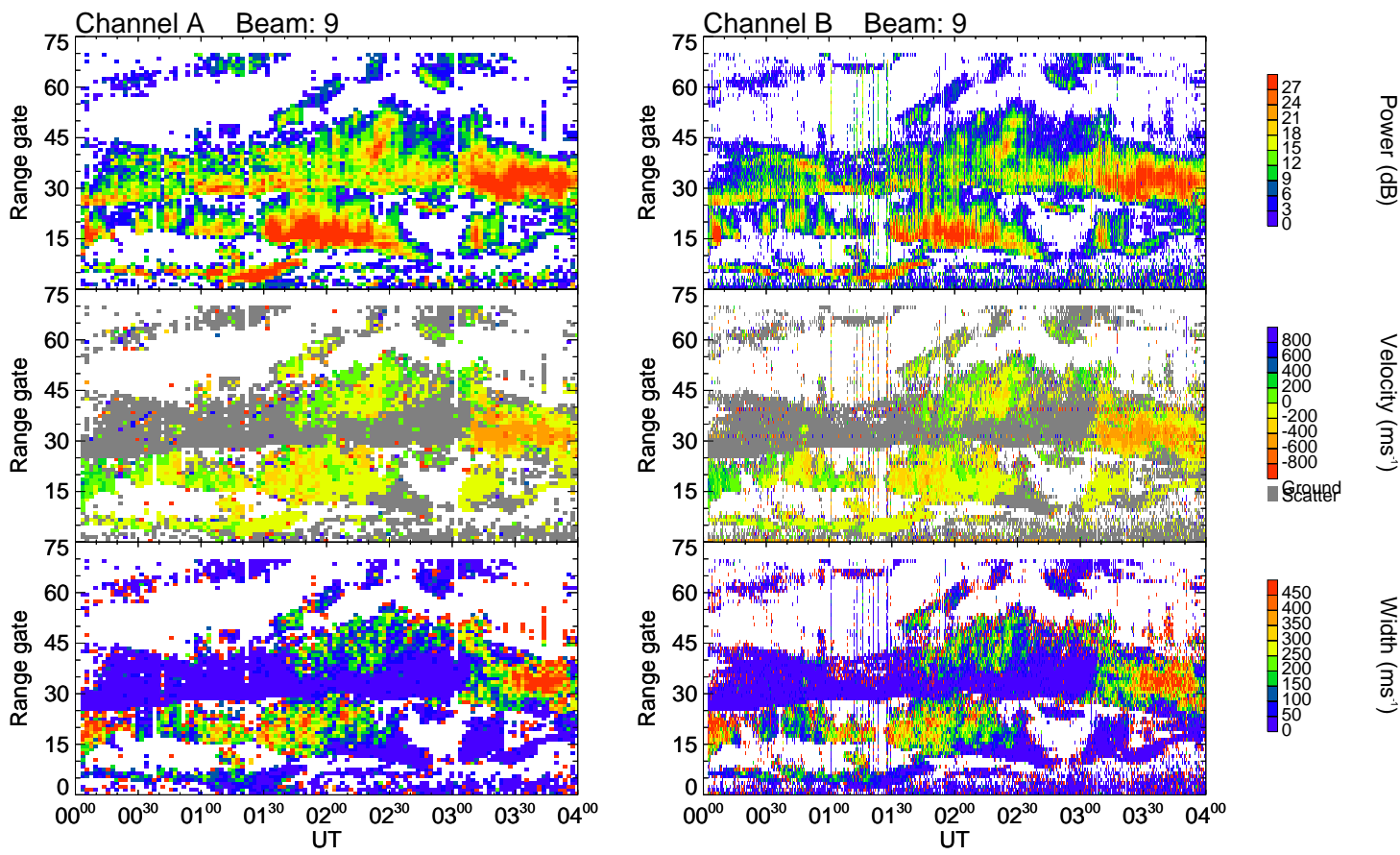

吕

\section{SUPERDARN PARAMETER PLOT}

Hankasalmi: width_I

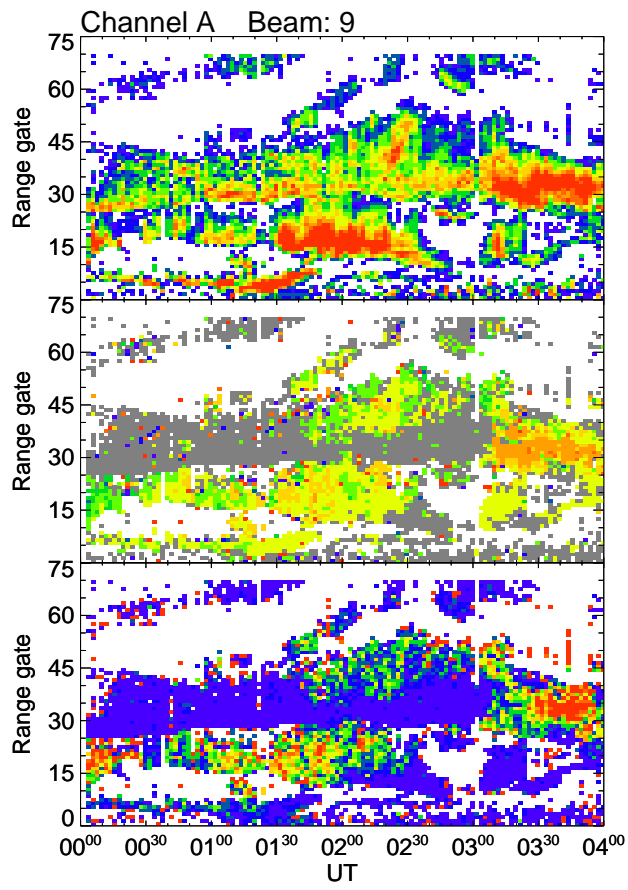

2 Jun $2002^{(153)}$

unknown scan mode (-26006)

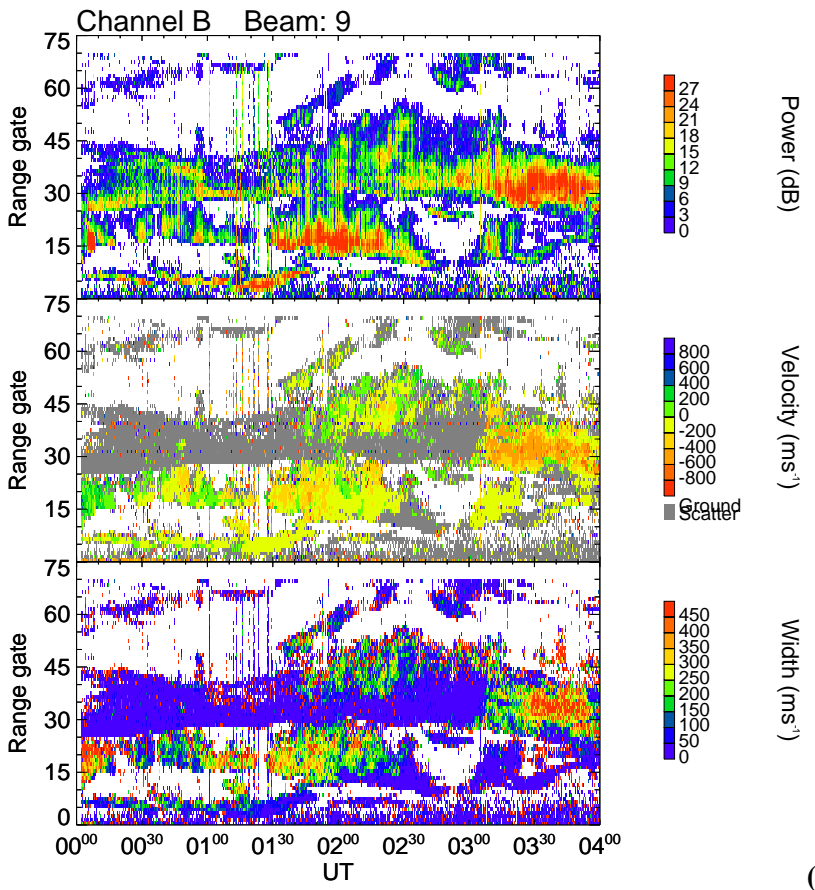

(b)

Fig. 5. Range time parameter plots for observations made from 00:00 to 04:00 UT on 2 June 2002. The data in the left-hand column are from a single beam of channel A running a full 16 beam scan, while the data in the right-hand column are from channel B which ran only on this beam. The parameters are from top to bottom backscatter power, line of sight velocity and spectral width. Figure 5a is for Hankasalmi, for which the beam is beam 9, and Fig. $5 b$ for Pykkvibaer, for which the beam is beam 5 . 
SUPERDARN PARAMETER PLOT Hankasalmi: width_I

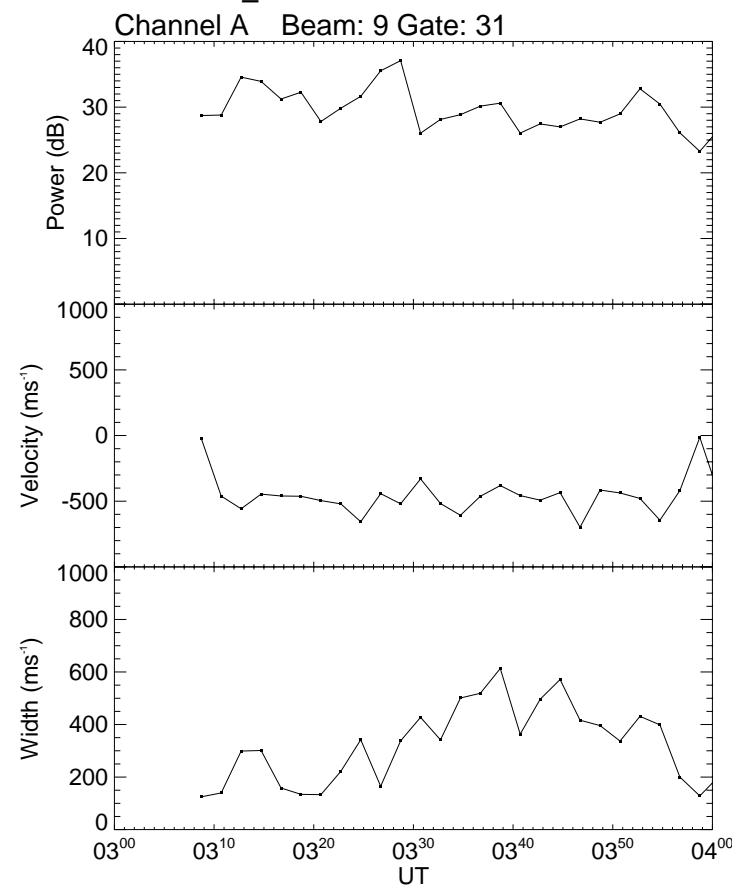

SUPERDARN PARAMETER PLOT

Pykkvibaer: width_I

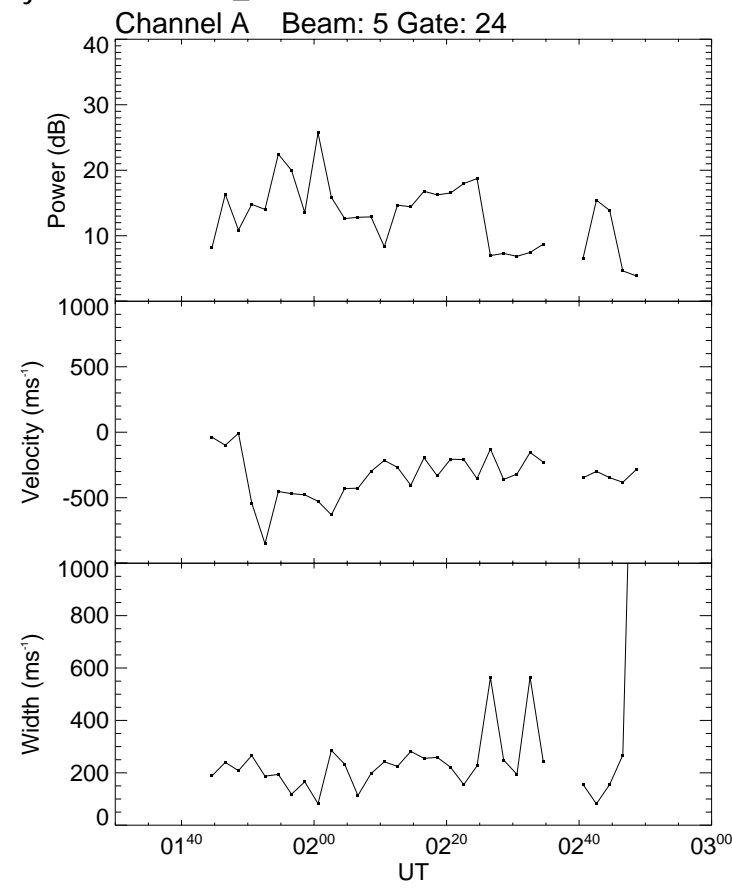

2 Jun $2002^{(153)}$

unknown scan mode $(-26006)$

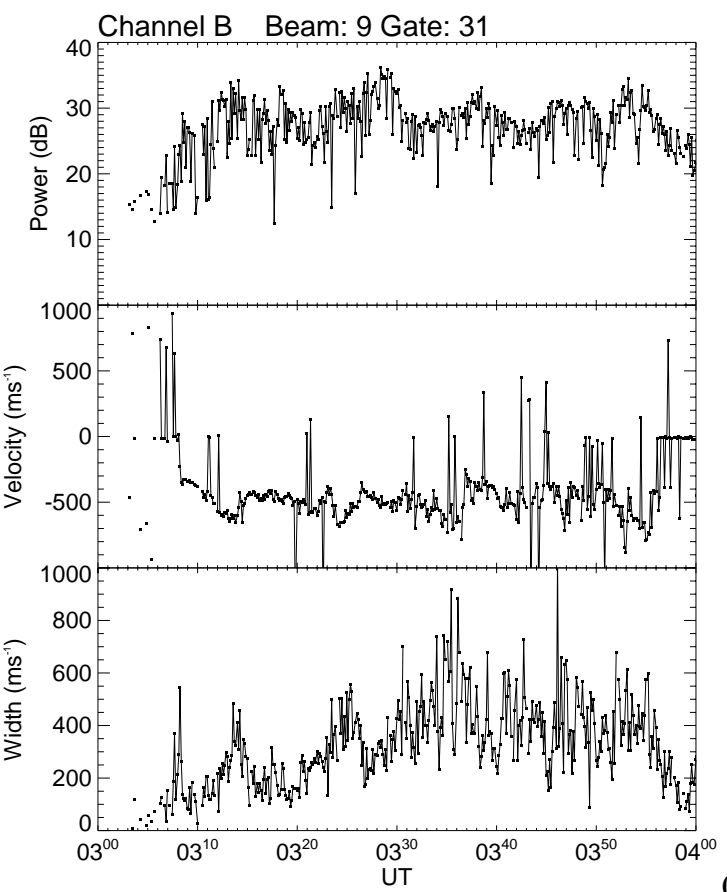

(a)

unknown scan mode $(-26006)$

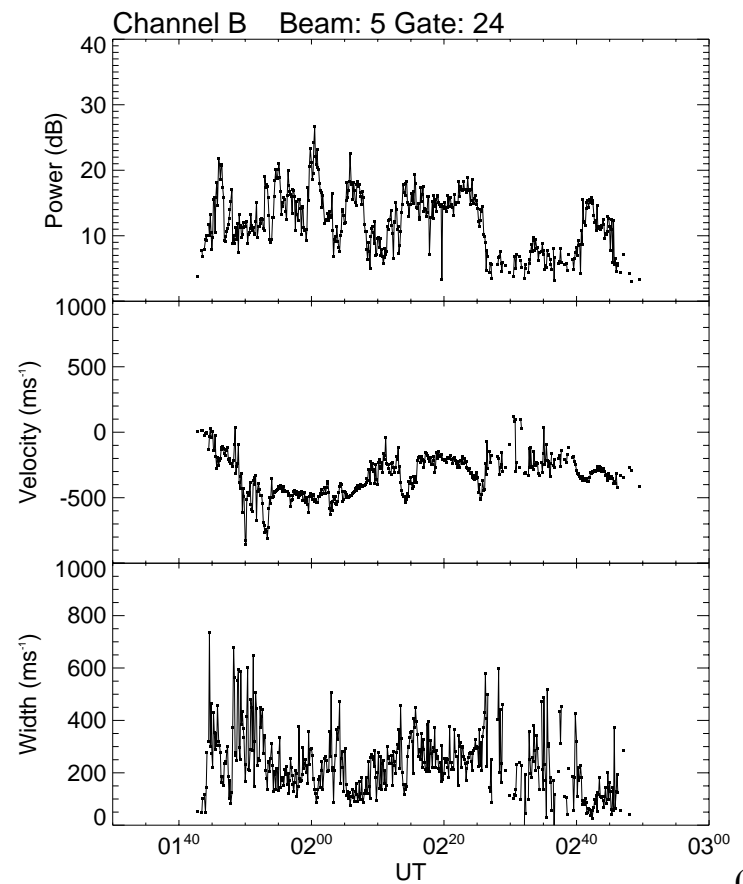

(b)

Fig. 6. Data from range gate 31 for the interval 03:00-04:00 UT on 2 June 2002 for Hankasalmi (Fig. 6a) and 01:30 to 03:00 UT on 2 June 2002 for Pykkvibaer (Fig. 6b). The parameters are from top to bottom backscatter power, line of sight velocity and spectral width. 


\section{SUPERDARN PARAMETER PLOT \\ Hankasalmi: width_I}
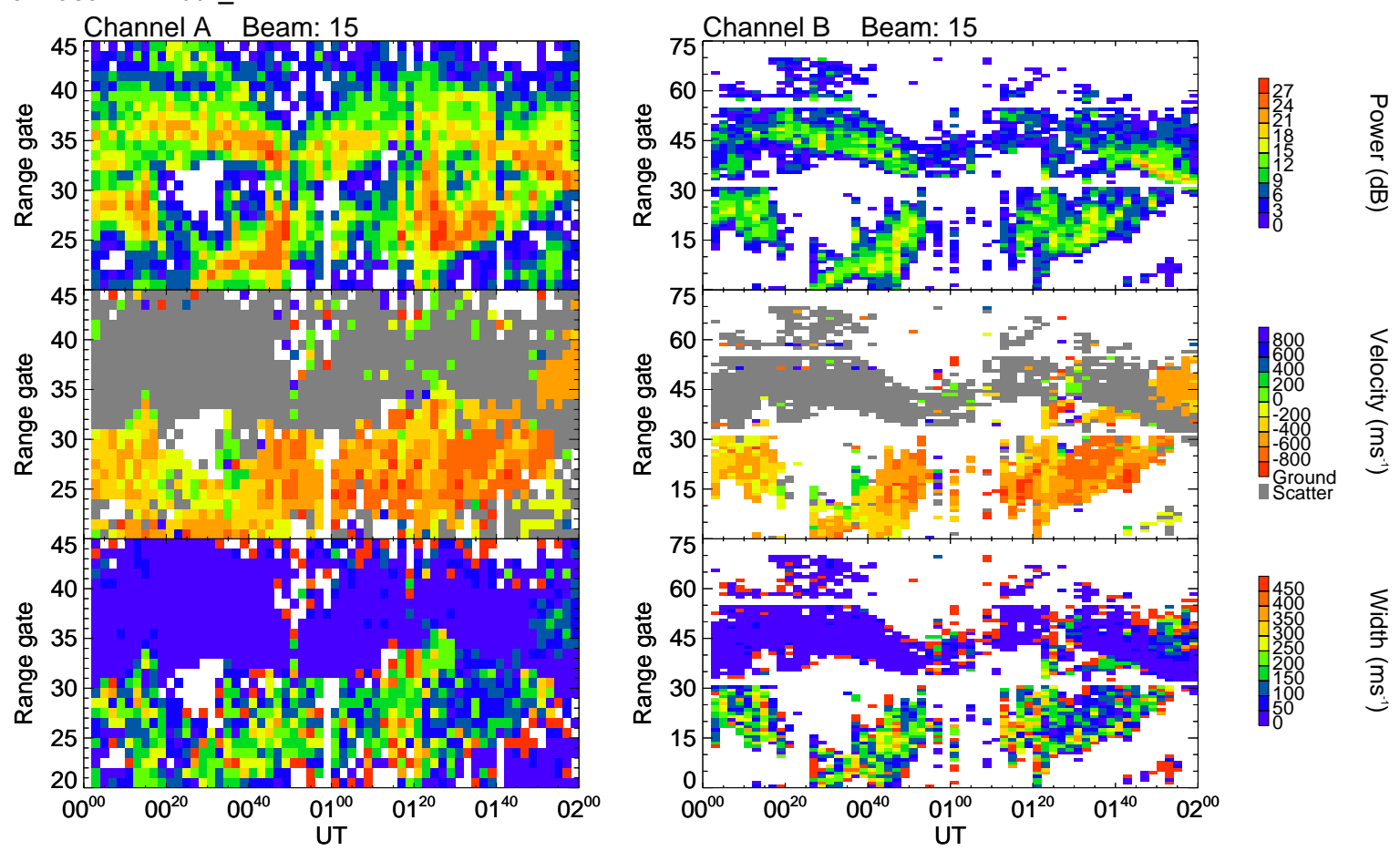

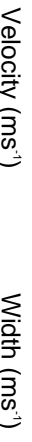

Fig. 7. Range time parameter plots for observations made from 00:00 to 02:00 UT on 14 June 2002. The basic format is the same as in Fig. 5 with channel A in the left-hand column and channel B in the right-hand column. For channel A we present 25 45-km range gates, while for channel $\mathrm{B}$ there are 70 15-km range gates which overlap with the gates shown from channel A.

(e.g. Robinson et al., 1997) and also to study E-region irregularities (e.g. Milan et al., 2001). However, when operating in this mode the full field of view of the radar is lost. The Stereo system can operate such that one channel has a range resolution of $15 \mathrm{~km}$ and the other of $45 \mathrm{~km}$, thereby allowing us to retain the large field of view when operating at improved range resolution.

Figure 7 presents range time parameter plots for beam 15 from the Hankasalmi CUTLASS radar for the two channels of Stereo for the interval 00:00-02:00 UT on 14 June 2002. In the left column we present the power, line of sight velocity, and spectral width from channel A for the range gates between 20 and 45 . The range resolution for channel $\mathrm{A}$ is $45 \mathrm{~km}$. The right column of Fig. 6 presents the same parameters for the same time interval but from channel B which was operating with a $15 \mathrm{~km}$ range resolution. Here we present all range gates. In this mode, the range to the first range gate for channel A was $180 \mathrm{~km}$ and for channel B it was arranged such that the $7015-\mathrm{km}$ range gates of channel B spanned gates 20 to 43 of channel A, thereby essentially overlapping with the gates shown in the left-hand panels of Fig. 7. A mixture of ground and ionospheric scatter is seen during this interval, with the ground scatter identified when the magnitude of the line of sight velocity is less than $50 \mathrm{~m} \mathrm{~s}^{-1}$ and the spectral width is less than $50 \mathrm{~m} \mathrm{~s}^{-1}$ (see Greenwald et al., 1995), and plotted as grey in the panels presenting velocity measurements in Fig. 7. We note that the power in channel B is normally less than that in channel $\mathrm{A}$, which we shall return to later. The line of sight velocity and spectral width, however, both indicate a good comparison between the two sets of data. There is again extra detail present from the improved spatial resolution in the gates from channel $\mathrm{B}$. We also note two range gates, 31 and 55, where there is no data which is caused by bad lags at these ranges.

The comparison between the two data sets is further demonstrated in Fig. 8, where we plot the value determined from the $45 \mathrm{~km}$ range gate for channel A against the average value from the three equivalent gates from channel $\mathrm{B}$, for each of the three parameters shown in Fig. 7. In Fig. 8 we have used data from all 16 beams of the scan, but we present only scatter which has been identified as ionospheric scatter in both channels. Concentrating first on the line of sight velocity (Fig. 8, central panel), we see that the velocity is clearly in good agreement between the two data sets. Likewise, the spectral width (Fig. 8, lower panel) shows a similar good agreement, although there is a "tail" of high values for channel B. The returned power of the signal (Fig. 8, upper panel) clearly demonstrates the reduction in power in channel B as compared to channel A. The figure demonstrates that this reduction is of the order of $10 \mathrm{~dB}$. Such a reduction is expected since the channel A range gate is three times the size of that of channel $\mathrm{B}$, and there should be three times 


\section{SUPERDARN PARAMETER PLOT}

\author{
Hankasalmi
}

14 Jun $2002^{(165)}$

stereo normal (ccw) scan mode (152)
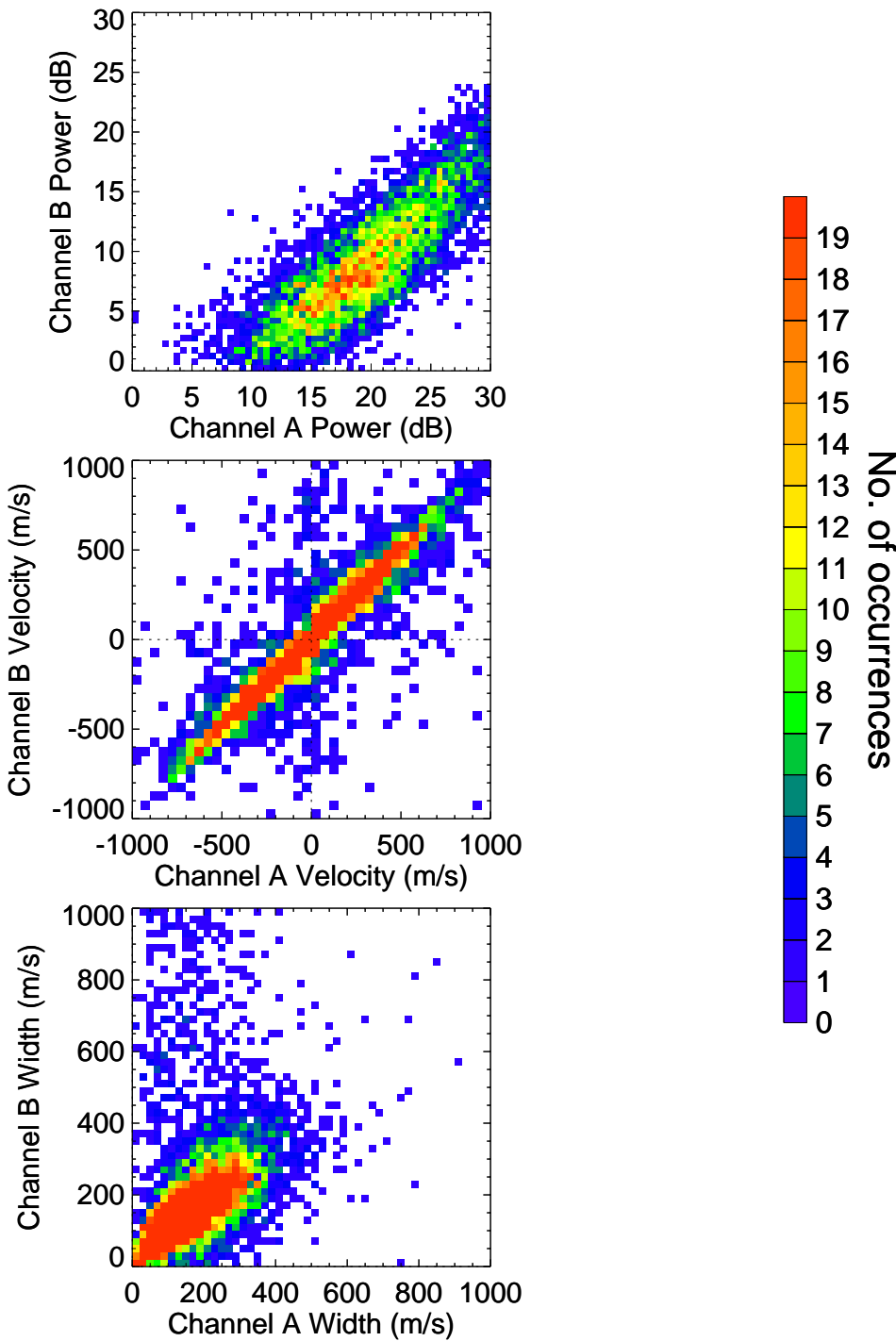

Fig. 8. Scatter plots of the backscatter power, line of sight velocity and spectral width of the ionospheric scatter from the interval shown in Fig. 7. Data from all 16 beams are presented and the data from the 45-km range gate have been compared with the average value for the three overlapping $15-\mathrm{km}$ range gates. Only scatter identified as ionospheric scatter have been presented.

the number of scatterers within a $45-\mathrm{km}$ gate compared to a $15-\mathrm{km}$ gate. This observation confirms the previous assumption that, in the case of ionospheric scatter, the irregularities, from which the radar signal is backscattered, are, in general, approximately uniformly distributed within a range gate.

\subsection{E-region irregularities}

A number of studies of E-region irregularities have been undertaken with the Pykkvibear CUTLASS radar (e.g. Milan and Lester, 2001; Milan et al., 2001). These studies have used a discretionary experimental mode, termed Myopic, in which the radar operates solely with a range resolution of $15 \mathrm{~km}$ and a dwell time on each beam of $3 \mathrm{~s}$. The first nonCommon Mode to be run with Stereo involved a run of Myopic, in which channel A operated at $10 \mathrm{MHz}$, while channel B changed the frequency at which it operated on consecutive scans. The frequency bands were $8,12,14,16$ and $18 \mathrm{MHz}$. The main purpose of this experiment was to investigate the wave number dependence of the ionospheric irregularity characteristics. Results from this first study have been presented elsewhere (Milan et al., 2003), but here we present a simple representation of a major new finding from this study. 

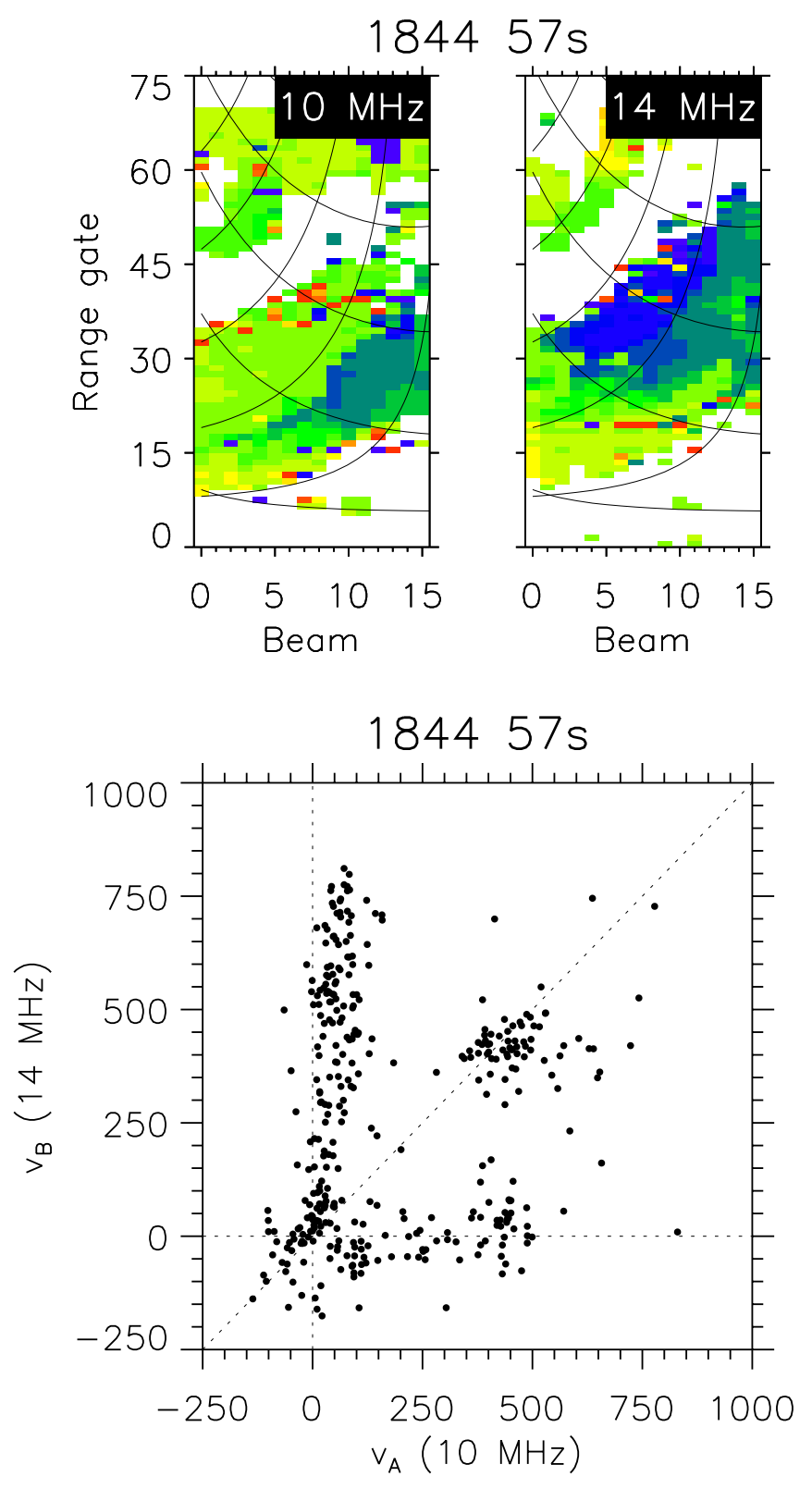

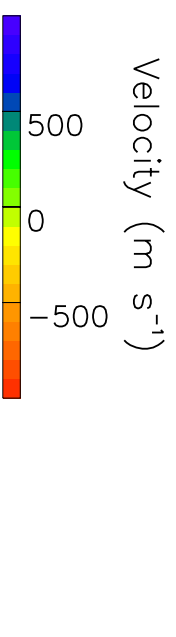

Fig. 9. In the top two panels the line of sight velocity from the two channels are presented for the same scan starting at 18:44:57 during a run of the Myopic experiment. Channel A (left panel) was operating at $10 \mathrm{MHz}$, while channel B (right panel) was operating at $14 \mathrm{MHz}$. The lower panel presents a scatter plot of the data shown in the upper two panels.
Figure 9 presents the line of sight velocity from the scan starting at 18:44:57 UTF for channel A, upper left panel, and channel B, upper right panel, as a function of range gate and beam. The curved lines superposed on each of these plots represent magnetic latitude and magnetic local time (MLT) co-ordinates. Channel A was operating at the constant frequency of $10 \mathrm{MHz}$, while channel B was operating at $14 \mathrm{MHz}$ for this particular scan. Based on interferometer data the scatter in the nearest range gates, out to gate 45 , is from the E-region, while the scatter from further gates is from the F-region. Here we concentrate solely on the E-region scatter. We note, that although the general location in range and beam of the scatter is very similar for the two frequencies, there is a major difference in the line of sight velocity at range gates greater than 30 for beams 3 to 12 . The line of sight velocity here is significantly larger at $14 \mathrm{MHz}$ than that at $10 \mathrm{MHz}$. Elsewhere, the line of sight velocity is very similar at the two frequencies. The lower panel of Fig. 9 presents a scatter plot of the data shown in the upper panel. There are essentially three distributions, one where the velocity is similar at the two frequencies, the second where the velocity at $14 \mathrm{MHz}$ is much higher than that at $10 \mathrm{MHz}$, and a third, smaller population, which occurs in a band at near ranges, where the opposite is true.

Milan et al. (2003) argue that the region of the high velocity scatter at $14 \mathrm{MHz}$ is from a higher altitude than the similar region at $10 \mathrm{MHz}$. The different frequency allows for the radar to probe a different altitude regime. The exact reason for the enhancement in the velocity, however, is not clear and requires further experimental and theoretical investiga- 
tion. Although a population of scatter from higher altitudes had been postulated previously by Milan et al. (2001), based on other information, this is the first opportunity to provide compelling experimental evidence for such an effect, as we are able to probe different altitudes with the two different frequencies due to the refraction of the radar signal as it propagates through the E-region plasma. It is important to point out that other experiments involving frequency scans would not be able to clearly demonstrate velocity differences, such as that presented in Fig. 9, as the time to repeat 6 different frequencies would be of the order of $5 \mathrm{~min}$, assuming a 3-s dwell time and no sychronisation. Only with the Stereo capability can one unambiguously demonstrate such a difference.

\section{Potential experimental modes}

The observations presented earlier have illustrated a number of possible experimental modes. Here we outline potential experimental modes which can be employed with this system, and of which there are three basic types. In the first, the system can be used to improve the temporal resolution, while in the second the system can be used more to improve the spatial resolution without losing spatial coverage, or to increase the spatial coverage of backscatter. The third type of experiment that the system can address is where two different types of experimental modes are operated simultaneously.

The improvement in the temporal resolution can be achieved in two basic ways. In the first, a single beam, or subset of beams, can be used on the second channel to support the standard mode running in the first channel, much like the experiment discussed in Sect. 3.1. This type of experiment would be ideal to investigate ULF waves with frequencies higher than Pc5 pulsations. The second way is to break down the field of view into two parts, such that the two channels can then be merged subsequently to give a complete field of view. This would reduce the temporal resolution for the complete scan by a factor of two, which could mean 30-s scans, if a dwell time of $3 \mathrm{~s}$ is used for each beam, and at best 8 -s scans with dwell times of $1 \mathrm{~s}$.

Improvements in spatial resolution can be achieved, in general, by reducing the pulse length, and we have demonstrated that the results from a $15-\mathrm{km}$ range gate are similar to those of a $45-\mathrm{km}$ range gate for line of sight velocity and spectral width. This has the disadvantage, already mentioned, that the total coverage of the field of view is reduced. Experiments have been run to look with higher spatial resolution for certain types of study. For example, the Myopic mode has been used to study E-region irregularities, at the expense of providing the full scan for the global convection maps. When using the CUTLASS radars in support of Heater experiments at Troms $\varnothing$, the smaller range resolution is also used, as the heater patch is limited to an approximately circular region of about $150 \mathrm{~km}$ diameter (e.g. Robinson et al., 1997). The spatial coverage can be recovered in full using Stereo, either with $45-\mathrm{km}$ range gates being used in the second channel, or partially recovered with $15-\mathrm{km}$ range gates with a different range to the first gate. It may also be possible to improve the coverage of scatter in certain circumstances by operating the two channels at widely different frequencies, such that different parts of the field of view are illuminated by the two channels. In addition, the frequency could be selected such that ground scatter can be optimized to investigate Atmospheric Gravity Waves (e.g. Bristow et al., 1994), while simultaneously using a different frequency to optimize ionospheric scatter and to ensure continued global measurements of the global convection pattern.

The most impressive possibility, however, is the capability of being able to run in two entirely different experimental modes. The main difference here would be that different pulse sequences would be transmitted for the two different channels. One might envisage that for certain scientific studies, a simple double pulse sequence would be sufficient. Such a pulse sequence could easily be incorporated into the Stereo capability, since the basic pulse separation could be achieved by just using the basic pulse separation of the current sequence, i.e. 2400 microseconds. Other more complex pulse sequences may also be employed, although the one limitation is that there could be no overlapping of pulses to be transmitted on both channels. The use of different pulse schemes may be particularly useful when studying irregularity generation mechanisms or artificial ionospheric scatter created during heating experiments. This will become particularly important in support of the new heater on Svalbard, SPEAR (Wright et al., 2000).

\section{Summary}

A new capability has been developed for the HF radars which form SuperDARN. This capability, known as Stereo, is only operational at the moment on the two radars which form CUTLASS. The development allows for the CUTLASS pair of radars to be operated in two entirely different experimental modes, within limits, thereby considerably enhancing the performance of the existing system, at a small extra cost. The system has been demonstrated with a variety of different types of experimental modes. Specifically, we have presented data from a run where high time resolution data have been recorded simultaneously with full scan data, which was a specific reason for the development of the Stereo system. In addition, we have demonstrated the ability to operate the two channels at different range gate lengths, illustrating a flexibility that will be required when undertaking heating experiments. Furthermore, we have demonstrated that scientifically important observations can also be made when operating the two channels at widely different frequencies.

Acknowledgements. The development of Stereo CUTLASS was supported through PPARC grant PPA/G/O/2001/00014, which also supported PJC, SJC, JAD, PH, KAM, SEM, MJP, DBP, ECT, JDT, and NMW. Routine CUTLASS Operations are supported by PPARC grant PPA/R/R/1997/00256.

The Editor in Chief thanks P. Dyson for his help in evaluating this paper. 


\section{References}

Arnold, N. F., Jones, T. B., Robinson, T. R., Stocker, A. J., and Davies, J. A.: Validation of the CUTLASS HF Radar Gravity Wave Observaing Capability using EISCAT CP-1 Data, Ann. Geophysicae, 16, 1392-1399, 1998.

Arnold, N. F., Robinson, T. R., Byrne, P. B., Lester, M., and Chapman, P. J.: Super Dual Auroral Radar Network HF Radar Observations of Fluctuations in the Spectral Distribution of Near Range Meteor Echoes in the Upper Mesosphere and Lower Thermosphere, Ann. Geophysicae, 19, 425-434, 2001.

Baker, K. B., Dudeney, J. R., Greenwald, R. A., Pinnock, M., Newell, P. T., Rodger, A. S., Mattin, N., and Meng, C.-I.: HF Radar Signatures of the Cusp and Low Latitude Boundary Layer, J. Geophys. Res., 100, 7671-7695, 1995.

Baker, K. B., Rodger, A. S., and Lu, G.: HF-radar observations of the dayside magnetic merging rate: A Geospace Environment Modelling boundary layer campaign study, J. Geophys. Res., 102, 9603-9617, 1997.

Bristow, W. A., Greenwald, R. A., and Samson, J. C.: Identification of High-Latitude Acoustic Gravity Wave Sources using the Goose Bay HF Radar, J. Geophys. Res., 99, 319-331, 1994.

Bristow, W. A., Otto, A., and Lummerzheim, D.: Substorm Convection Patterns Observed by the Super Dual Auroral Radar Network, J. Geophys. Res., 106, 24 593-24 609, 2001.

Chisham, G., Pinnock, M., Coleman, I. J., Hairston, M. R., and Walker, A. D. M.: An unusual geometry of the ionospheric signature of the cusp: implications for magnetopause merging sites, Ann. Geophysicae, 20, 29-40, 2002.

Davies, J. A., Yeoman, T. K., Rae, I. J., Milan, S. E., Lester, M., and McWilliams, K. A.: Ground-based observations of the auroral zone and polar cap ionospheric responses to dayside transient reconnection, Ann. Geophysicae, 20, 781-794, 2002.

Dudeney, J. R., Rodger, A. S., Freeman, M. P., Pickett, J., Scudder, J., Sofko, G., and Lester, M.: The Nightiside Ionospheric Response to IMF By Changes, Geophys. Res. Lett., 25, 26012604, 1998.

Greenwald, R. A., Baker, K. B., Hutchins, R. A., and Hanuise, C.: An HF Phased-Array Radar for Studying Small-Scale Structure in the High-Latitude Ionosphere, Rad. Sci., 20, 63-79, 1985.

Greenwald, R. A., Baker, K. B., Dudeney, J. R., Pinnock, M., Jones, T. B., Thomas, E. C., Villain, J.-P., Cerisier, J.-C., Senior, C., Hanuise, C., Hunsucker, R. D., Sofko, G., Koehler, J., Nielsen, E., Pellinen, R., Walker, A. D. M., Sato, N., and Yamagishi, H.: DARN/SuperDARN: A Global View of the Dynamics of the high-Latitude Convection, Space Sci. Rev., 71, 761-796, 1995.

Grocott, A., Cowley, S. W. H., and Sigwarth, J. B.: Ionospheric flow during extended intervals of northward but By-dominated IMF, Ann. Geophysicae, 21, 509-538, 2003.

Hall, G. E., MacDougall, J. W., Moorcroft, D. R., and St.-Maurice, J.-P.: Super Dual Auroral Radar Observations of Meteor Echoes, J. Geophys. Res., 102, 14 603-14 614, 1997.

Hughes, J. M., Bristow, W. A., Greenwald, R. A., and Barnes, R. J.: Determining characteristics of HF communications links using SuperDARN, Ann. Geophysicae, 20, 1023-1030, 2002.

Lester, M., Milan, S. E., Besser, V., and Smith, R.: A Case Study of HF Radar Spectra and $630.0 \mathrm{~nm}$ Auroral Emission in the Pre Midnight Sector, Ann. Geophysicae, 19, 327-339, 2001.

Makarevitch, R. A., Koustov, A. V., Sofko, G. J., Andre, D., and Ogawa, T.: Mutifrequency measurements of HF Doppler velocity in the auroral E region, J. Geophys. Res., 107, 10.1029/2001JA000268, 2002.
Milan, S. E. and Lester, M.: A Classification of Spectral Populations Observed in HF Radar Backscatter from the E Region and Lower F Region Auroral Electrojets, Ann. Geophysicae, 19, 189-204, 2001.

Milan, S. E., Lester, M., Cowley, S. W. H., and Brittnacher, M.: Convection and Auroral Response to a Southward Turning of the IMF: Polar UVI, CUTLASS and IMAGE Signatures of Transient Magnetic Flux Transfer at the Magnetopause, J. Geophys. Res., 105, 15 741-15 755, 2000.

Milan, S. E., Lester, M., Sato, N., and Takizawa, H.: On the Altitude Dependence of the Spectral Characteristics of Decamtrewavelength E Region Backscatter and the Relationship with Optical Auroral Forms, Ann. Geophysicae, 19, 205-217, 2001.

Milan, S. E., Lester, M., and Sato, N.: Multi-frequency observations of E region HF radar aurora, Ann. Geophysicae, 21, 761-777, 2003.

Neudegg, D. A., Yeoman, T. K., Cowley, S. W. H., Provan, G., Haerendel, G., Baumjohann, W., Aster, U., Fornacon, K.-H., Georgescu, E. and Owen, C. J.: A Flux Transfer Event Observed at the Magnetopause by the Equator-S Spacecraft and in the Ionosphere by the CUTLASS HF Radar, Ann. Geophysicae, 17, 707-711, 1999.

Neudegg, D. A., Cowley, S. W. H., Milan, S. E., Yeoman, T. K., Lester, M., Provan, G., Haerendel, G., Baumjohann, W., Nikutowski, B., Buchner, J., Aster, U., Fornacon, K.-H., and Georgescu, E.: A Surevy of Magnetpause FTEs and Associated Flow Bursts in the Polar Ionosphere, Ann. Geophysicae, 18, 416-435, 2000.

Pinnock, M., Rodger, A. S., Dudeney, J. R., Baker, K. B., Newell, P. T., Greenwald, R. A., and Greenspan, M. E.: Observations of an Enhanced Convection Channel in the Cusp Ionosphere, J. Geophys. Res., 98, 3767-3776, 1993.

Provan, G., Yeoman, T. K., and Milan, S. E.: CUTLASS Finland Radar Observations of the Ionospheric Signatures of Flux Transfer Events and Resulting Plasma Flows, Ann. Geophysicae, 16, 1411-1422, 1998.

Robinson, T. R., Stocker, A. J., Bond, G. E., Eglitis, P., Wright, D. M., and Jones, T. B.: O- and X-Mode Heating Effects Observed Simultaneously with the CUTLASS and EISCAT Radars and Low Power HF Diagnostics at Troms $\varnothing$, Ann. Geophysicae, 15, 134-136, 1997.

Ruohoniemi, J. M. and Baker, K. B.: Large-Scale Imaging of HighLatitude Convection with Super Dual Auroral Radar Network HF Radar Observations, J. Geophys. Res., 103, 20 797-20 811, 1998.

Ruohoniemi, J. M. and Greenwald, R. A.: Statistical Patterns of High-Latitude Convection Obtained from Goose Bay HF Radar Observations, J. Geophys. Res., 101, 21 743-21 763, 1996.

Ruohoniemi, J. M., Barnes, R. J., Greenwald, R. A., and Shepherd, S. G.: The Response of the High-Latitude Ionosphere to the Cororanl Mass Ejection of 6 April 2000: A Practical Demonstration of Space Weather Nowcasting with the Super Dual Auroral Radar Network HF Radars, J. Geophys. Res., 106, 30085 $30097,2001$.

Senior, C., Cerisier, J.-C., Rich, F. J., Lester, M., and Parks, G. K.: Strong sunward propagating flow bursts in the night sector during quiet solar wind conditions: SuperDARN and satellite observations, Ann. Geophysicae, 20, 771-779, 2002.

Thorolfsson, A., Cerisier, J.-C., Lockwood, M., Sandholt, P. E., Senior, C., and Lester, M.: Simultaneous optical and radar signatures of poleward moving auroral forms, Ann. Geophysicae, 18, 1054-1066, 2000. 
Walker, A. D. M., Pinnock, M., Baker, K. B., Dudeney, J. R., and Rash, J. P. S.: Strong flow bursts in the nightside ionosphere during extremely quiet solar wind conditions, Geophys. Res. Lett., 25, 881-884, 1998.

Wild, J. A., Cowley, S. W. H., Davies, J. A., Khan, H., Lester, M., Milan, S. E., Provan, G., Yeoman, T. K., Balogh, A., Dunlop, M. W., Fornacon, K.-H., and Georgescu, E.: First Simultaneous Observations of Flux Transfer Events at the High-Latitude Magnetopause by the Cluster Spacecraft and Pulse Radar Signatures in the Conjugate Ionosphere by the CUTLASS and EISCAT Radars, Ann. Geophysicae, 19, 1491-1508, 2001.

Woodfield, E. E., Davies, J. A., Eglitis, P., and Lester, M.: A Case Study of HF Radar Spectral Width in the Post Midnight Magnetic Local Time Sector and its Relationship to the Polar Cap
Boundary, Ann. Geophysicae, 20, 501-509, 2002.

Wright, D. M., Davies, J. A., Robinson, T. R., Chapman, P. J., Yeoman, T. K., Thomas, E. C., Lester, M., Cowley, S. W. H., Stocker, A. J., Horne, R. B., and Honary, F.: Space Plasma Exploration by Active Radar (SPEAR): An overview of a future radar facility, Ann. Geophysicae, 18, 1248-1255, 2000.

Yeoman, T. K., Wright, D. M., Robinson, T. R., Davies, J. A., and Rietveld, M.: High Spatial and Temporal Resolution Observations of an Impluse-Driven Field Line Resonance in Radar Backscatter Artificially Generated with the Troms $\varnothing$ Heater, Ann. Geophysicae, 15, 634-644, 1997.

Yeoman, T. K., Davies, J. A., Wade, N. M., Provan, G., and Milan, S. E.: Combined CUTLASS, EISCAT and ESR Observations of an Isolated Substorm, Ann. Geophysicae, 18, 1073-1087, 2000. 